\title{
DESIGN CRITERIA FOR SCANTLING OF LONGITUDINAL AND TRANSVERSE CONNECTIONS IN THE TORSION BOX UNDER FATIGUE LOADING
}

\author{
Arturo Silva-Campillo* \\ Juan Carlos Suárez-Bermejo \\ Miguel Ángel Herreros-Sierra \\ Universidad Politécnica de Madrid, Spain
}

*Corresponding author: a.silva@upm.es (A. Silva-Campillo)

\begin{abstract}
Fatigue is one of the main failure modes in marine structures, and it is caused by the strong cyclic characteristics of the loads they support. This failure mode is amplified in areas of high stress concentration, such as at the intersection of primary and secondary elements. In this paper, a two-phase study is proposed that compares numerical and experimental results using a digital image correlation technique. The described procedure establishes selection, design, and scantling criteria and provides recommendations for the design of the transverse structure using specimens with different geometries. These geometries correspond to different designs for the transverse primary structure that use a longitudinal secondary stiffener with variable thickness and longitudinal spacing to transverse in a dynamic and quasi-static regime. The stress state for this regime is calculated based on the biaxiality indication concept, which uses the fatigue phenomenon (safety factor and sensitivity curves) and fracture mechanics (parameters of the Paris crack propagation law, correlation value, and law of variation of the stress intensity factor).
\end{abstract}

Keywords: Fatigue life; ship structures; crack growth; fracture.

\section{INTRODUCTION}

Fatigue is a local phenomenon caused by fluctuating stresses on the structure that originate from global and local loads on the hull girder. In terms of the fatigue event, structural details that have high stress concentrations are of particular interest. To this end, the cut-outs made in the primary transverse structure to allow passage of the element structure (longitudinal stiffeners), which is a structural element in all ships and offshore structures, has been widely studied and investigated to optimize it in terms of structural performance [1].

This structure has been analyzed under the influence of adjoining substructures [2], wherein the cut-out geometry and lug or collar plate presence with the respective longitudinal stiffener are established using finite element models (FEM) and hypotheses with shell and solid elements. To this end, different approaches have been used [3], including nominal stress, structural or hot-spot stress, notch stress and notch intensity, notch strain, and the crack propagation process. Over the years, several procedures have been developed to implement the most appropriate study methodology [4] for a structural hot-spot in welded joints based on the results of different experimental tests involving four different geometries.

These structural details have been studied for all types of vessels. For example, Fricke and Paetzold [5] tested different constant and variable amplitude history loads to determine the fatigue phenomenon in different areas of container ships (hatch corner and upper wing torsional box) for identifying the intersection of the primary and secondary structure for different load values. The results were validated with those obtained via FEM using the structural hot-pot stress and effective notch stress approaches. Lotsberg [6] presented a summary with different methodologies to evaluate fatigue life based on the hot-spot stress approach and the corresponding SN curve in engineering practice, fatigue strength is defined from the so-called SN curves [7] - for this structural detail in floating, 
production, storage, and offloading (FPSO) units. SN curves are used to calculate the fatigue life of this type of structure [5], where the results are validated through experimental tests. The damage and fatigue life of this structure is studied using FEM of the structural details of double hull oil tankers based on the notch stress approach; furthermore, the nonlinear corrosion effect on fatigue life was investigated [8].

It is common to use numerical analysis by FEM to evaluate the stresses via fatigue analysis; it is possible to view a detailed analysis of this type of structure that considers the welding between elements using the FEM analysis [9]. The results of the fatigue analysis performed using the FEM of the structural detail are verified through comparison of different procedures to evaluate fatigue life [10]. Fatigue life analysis has been conducted using a fracture mechanics approach [11], wherein the effects of misalignment on the weld of the structure or intersection are investigated, and a FEM tool is proposed to calculate the weld effect on the sub model without considering crack propagation.

This research proposes scantling criteria that are based on obtaining structural results via the evaluation of the different alternatives of the design variables (spacing of the longitudinal stiffeners and thickness of primary supporting member in the torsion box of a container ship; Fig. 1) of two different geometries that are commonly used in the shipbuilding industry. Experimental tests are conducted to validate the numerical results, provide maximum reliability, and to allow the results for scantlings of ship structures to be used.

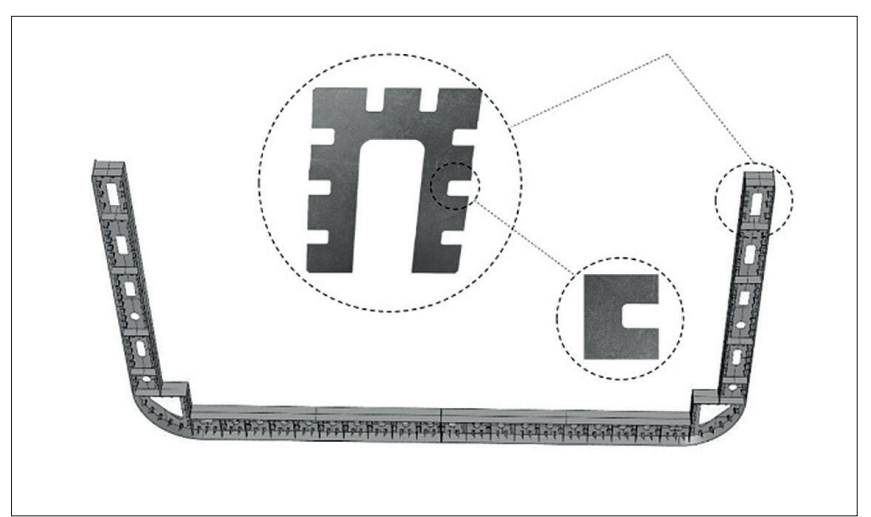

Fig. 1. Midship section of the container ship with an upper wing torsional box and cut-out detail

The study is outlined as follows: Section 2 gives the mathematical basis and section 3 introduces the experimental tests by presenting the specimens and their coupling in the testing machine. Section 4 details the finite element modelling of the specimens and compares it with the test specimens to validate the obtained results. Section 5 presents the results with respective discussion, and finally, section 6 provides the conclusions resulting from this research.

\section{FATIGUE DAMAGE ASSESSMENT}

The study is conducted in two phases based on the state of the structure in terms of damage. The first level corresponds to the analysis of crack initiation from the perspective of the fatigue phenomenon (using the Palmgren-Miner linear damage hypothesis), and the second phase is characterized by the study of crack propagation based on fracture mechanics.

\section{MIXED-MODE CRACK GROWTH PATH}

Several analytical models have been developed for isotropic solids from various mathematical developments [12-14] to establish the direction of crack propagation [15-16]. The maximum circumferential stress (MCS) theory is the most widely used due to its simple, easily implementable, and good results [17]. This theory proposes the following concept to obtain the direction of crack propagation from the circumferential tensile stress $\left(\partial \sigma_{\theta \theta}\right)$ :

$$
\frac{\partial \sigma_{\theta \theta}}{\partial \theta}=0 y \frac{\partial^{2} \sigma_{\theta \theta}}{\partial^{2} \theta}<0 \Rightarrow \theta \mid \sigma_{\theta \theta, \max }
$$

To find the angle of propagation $\theta$, it is necessary to identify the direction in which the tangential stress $\left(\tau_{r \theta}\right)$ is zero, that is,

$$
\begin{gathered}
\frac{\partial \sigma_{\theta \theta}}{\partial \theta}=0 \Rightarrow \tau_{r \theta}=0 \\
\frac{1}{4} K_{I}\left(\sin \frac{\theta}{2}+\sin \frac{3 \theta}{2}\right)+\frac{1}{4} K_{I I}\left(\cos \frac{\theta}{2}+3 \cos \frac{3 \theta}{2}\right)= \\
\frac{1}{2} \cos \frac{\theta}{2}\left[K_{I} \sin \theta+K_{I I}(3 \cos \theta-1)\right]=0
\end{gathered}
$$

The following solutions are proposed using the presented criterion:

$$
\left\{\begin{array}{l}
\theta= \pm \pi \\
K_{I} \sin \theta+K_{I I}(3 \cos \theta-1)=0
\end{array}\right.
$$

The first solution is trivial and corresponds to the faces of the crack. The most common way in which the second solution can be found corresponds to

$$
\begin{aligned}
\theta \mid \sigma_{\theta \theta, \max }= & \Delta \theta=2 \tan ^{-1}\left[\frac{K_{I}-\sqrt{K_{I}^{2}+8 K_{I I}^{2}}}{4 K_{I I}}\right] \text { if } \quad K_{I I}<0 \\
\theta \mid \sigma_{\theta \theta, \text { max }}= & \Delta \theta=-2 \tan ^{-1}\left[\frac{K_{I}-\sqrt{K_{I}^{2}+8 K_{I I}^{2}}}{4 K_{I I}}\right] \text { if } K_{I I}<0 \\
& \theta \mid \sigma_{\theta \theta, \text { max }}=\Delta \theta=0 \quad \text { if } \quad K_{I I}=0
\end{aligned}
$$

For the crack to extend, the maximum circumferential tensile stress obtained in Eq. (4) must reach a critical value, which is obtained by rearranging the components as

$$
\sigma_{\theta \theta} \sqrt{2 \pi r}=K_{I C}=\cos \frac{\theta}{2}\left[K_{I} \cos ^{2} \frac{\theta}{2}-\frac{3}{2} K_{I I} \sin \theta\right]
$$

Eq. (5) can be normalized as

$$
\frac{K_{I}}{K_{I C}} \cos ^{3} \frac{\theta}{2}-\frac{3}{2} \frac{K_{I I}}{K_{I C}} \cos \frac{\theta}{2} \sin \theta=1
$$

Finally, Eq. (7) is used to define an equivalent stress intensity factor based on the implementation of each of the fracture modes as

$$
K_{e q}=K_{I} \cos ^{3} \frac{\theta}{2}-\frac{3}{2} K_{I I} \cos \frac{\theta}{2} \sin \theta
$$




\section{TESTING}

\section{DESIGN AND FABRICATION OF TEST SPECIMENS}

Three values of longitudinal spacing (s) (400, 500, and 600 $\mathrm{mm}$ ) are established to study and characterize the structural behavior. The initial structure comprising multiple cut-outs is simplified and modeled by the assumption adopted in Fig. 2, which allows a single cut-out under the influence of the proximity of contiguous cut-outs to be analyzed by following a procedure similar to Fricke et al. [1].

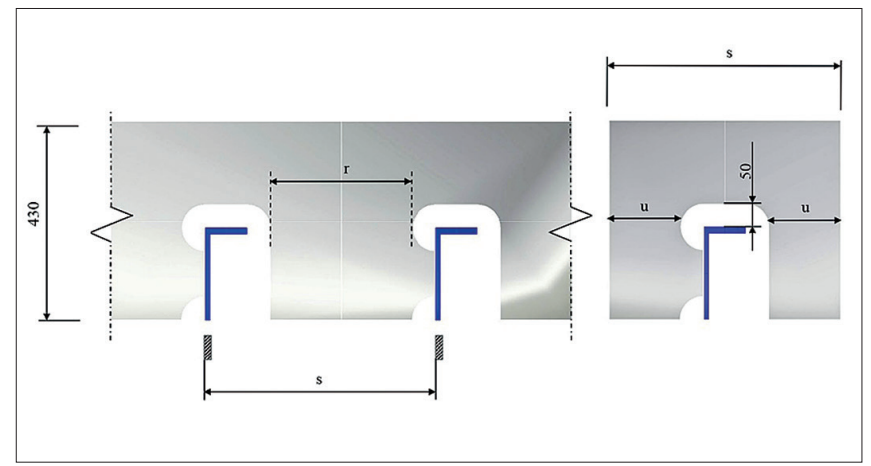

Fig. 2. Modelling of isolated structure of interest. Dimensions in $\mathrm{mm}$

Table 1 shows the dimensions of each of the specimens as a function of the longitudinal spacing values.

Tab. 1. Dimensions (in $\mathrm{mm}$ ) of the sub model for each different spacing value

\begin{tabular}{|c|c|c|}
\hline $\mathrm{s}$ & $\mathrm{r}$ & $\mathrm{u}$ \\
\hline 400 & 210 & 105 \\
\hline 500 & 310 & 155 \\
\hline 600 & 410 & 205 \\
\hline
\end{tabular}

The specimen is adjusted based on the numerical results for the $500 \mathrm{~mm}$ spacing with the correcting geometric scale factor between the original ship structure and that measured in the test laboratory. This study involves two typical geometries commonly used in the shipbuilding industry. These geometries are for the primary supporting members that allow the secondary longitudinal stiffener to pass under a uniformly distributed tensile load. This issue is simulated by four point loads acting on each of the eight holes in the specimen that serve to distribute the design load and establish the structure in the testing machine. Fig. 3 shows the two test specimens and their respective dimensions located on a steel plate with dimensions $360 \times 215 \times 10 \mathrm{~mm}$ (the initial design geometry is located on a $430 \times 500 \times 20 \mathrm{~mm}$ plate; it is scaled with a geometric scale factor of two in all three dimensions to couple it to the testing machine). The material properties (provided by the manufacturer's certificate) are a Young's modulus and Poisson's ratio of $206 \mathrm{GPa}$ and 0.3 , respectively, with a $250 \mathrm{MPa}$ yield stress and a steel density of $7.85 \mathrm{t} / \mathrm{m}^{3}$.
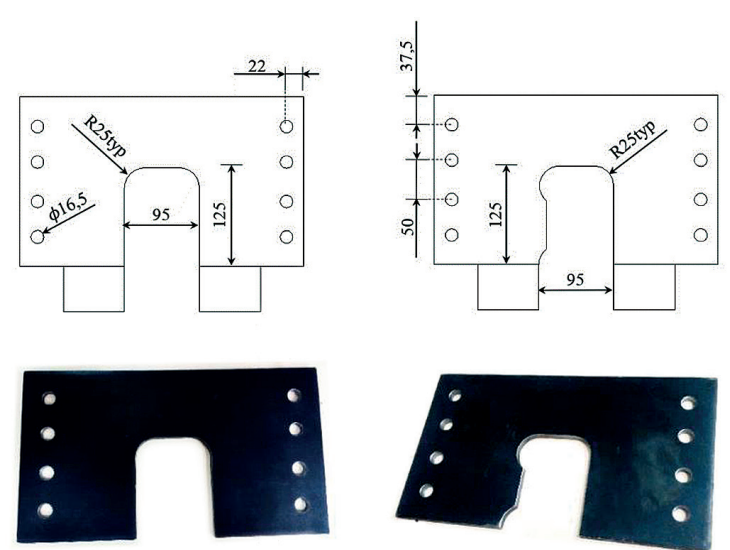

Fig. 3. Sketch and dimensions (in mm). (left) Specimen 1, (right) Specimen 2

The crack growth rate in a linear regime is established as a criterion for comparison between the two specimens; therefore, a pre-crack is located to focus on crack propagation, as reported by Carpintieri [18]. Using the same criteria employed by Strandberg [19], the same pre-crack dimension $(6 \mathrm{~mm})$ is located for each of the proposed models, and they are oriented perpendicular to the upper region of the cut out. Using the same principles as those in the establishment of the geometries of the test specimens (single-edge notched tension, SENT), the initial regular load condition undergoes the same scaling process under a factor of 2.5 and within the range of $\pm 25 \%$ about the mean stress $(R=0.6)$. The design fatigue load is defined using a value $\mathrm{R}=-1$.

\section{INSTRUMENTATION AND CONDITIONING OF THE SPECIMENS}

The test procedure is performed using the digital image correlation (DIC) technique widely used in fatigue phenomenon [20], which allows validation criteria to be established by obtaining displacements and deformations to provide the maximum reliability to the process. The distribution of the strains and displacements in the specimens are obtained using the Open-Source 2D software Ncorr ${ }^{\oplus}$ together with MATLAB $^{\circledR}$ [21]. The procedure is performed in a quasi-static regime (constant load speed of $0.5 \mathrm{kN} / \mathrm{s}$ until a generic calibration load of $130 \mathrm{kN}$ is reached), and it requires some prerequisites in terms of surface treatment through a previous cleaning with acetone. The application of the white contrast paint (PFINDER ${ }^{\circledR} 280$ ) and the indirect spraying of black paint serves as a random mesh for each of the specimens (Fig. 4).

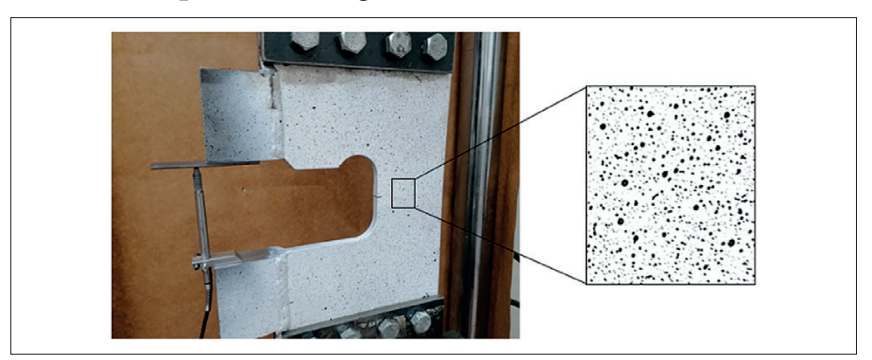

Fig. 4. Experimental specimen 2 meshing for digital image correlation application 


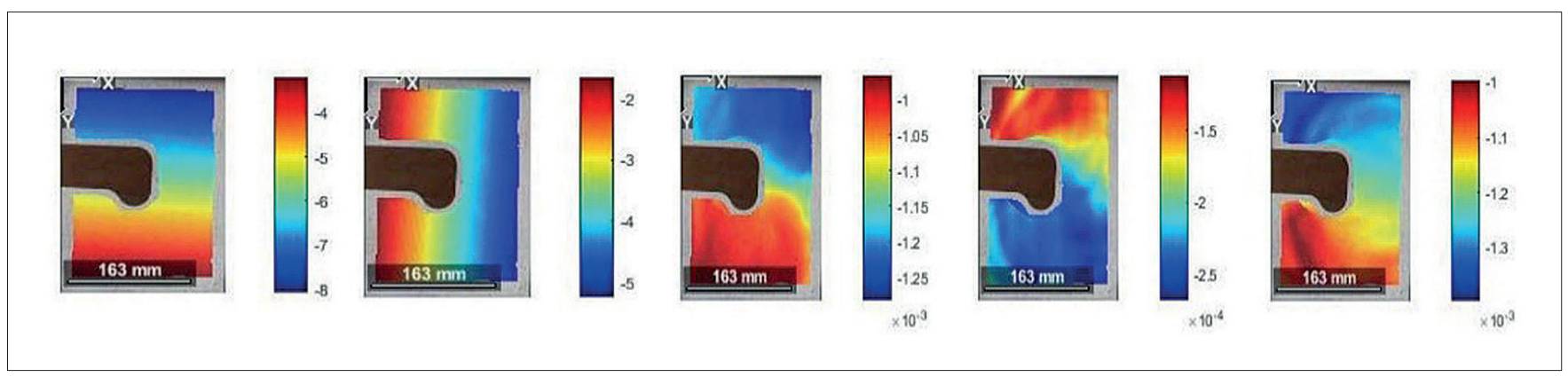

Fig. 5. Displacement and strain distributions for quasi-static load $130 \mathrm{kN}\left(\mathrm{U}(\mathrm{mm}), \mathrm{V}(\mathrm{mm}), \varepsilon_{x x}\left(\mathrm{~mm} / \mathrm{mm} Y_{x y}(\mathrm{~mm} / \mathrm{mm}), \varepsilon_{y y}(\mathrm{~mm} / \mathrm{mm})\right)\right.$

The process is recorded with a video camera, and the video is decomposed into a set of images. These images are processed using the program, and the meshes of the points of each image are compared; they correspond to different moments of the test. Fig. 5 shows the obtained output parameters of the program for a previous calibration specimen. The procedure is assessed using the inclusion of another calibration load and the two remaining specimen geometries.

\section{FATIGUE TESTING}

The test specimens are fitted in the dynamic testing machine by machining two transition blocks coupled in the parts of the machine intended for this purpose (Fig. 6); the upper transition block is connected to the specimen (previously drilled in four points) through four bolts subjected to double shear throughout the process, whereas the connection with the upper load cell is achieved by the joint combination of a lyre shackle with its respective pin and rotating eyebolt. This approach is employed to absorb the possible imperfections of the arranged welds (between different elements that constitute the transition blocks) or possible misalignments (concentric or angular) of the testing machine, which can induce undesirable bending loads in the model that may interfere with the results and reduce the reliability of the process.

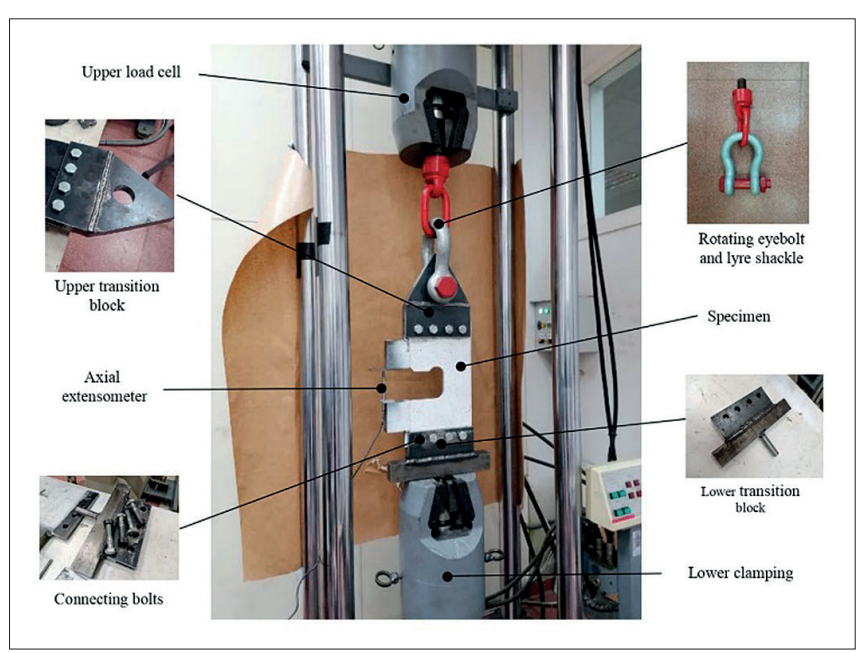

Fig. 6. Testing machine (INSTRON ${ }^{\circledast} 500 \mathrm{kN}$ ) arrangement

The connection of the model with the lower clamp is achieved through a lower transition block composed of a U-shaped machined piece (previously drilled in four points in an identical manner as the upper transition block) that fits the model using four bolts. The connection of the transition block with the lower clamping is developed by including a parallelepiped element to which a threaded hole is drilled where a cylindrical component is subsequently welded to the previous element, which is then attached using the lower clamp. To characterize the results, the design frequency of the regular load introduced to the model from the upper load cell is set to $5 \mathrm{~Hz}$ based on the procedure reported by Branco et al. [22].

The original model of study is characterized by a welding in the mouth of the same one that is included in the numerical simulation by means of a fixed support. Owing to the characteristics of the testing machine, the boundary conditions are modified by suppressing the fixed support that corresponds to the lower clamp of the testing machine; the previous idealization that corresponds to the welding located in the lower mouth is suppressed to ensure correct correlation and achieve accurate results. The initial design load is simulated by means of four point loads whose contribution is the total load (Fig. 7).

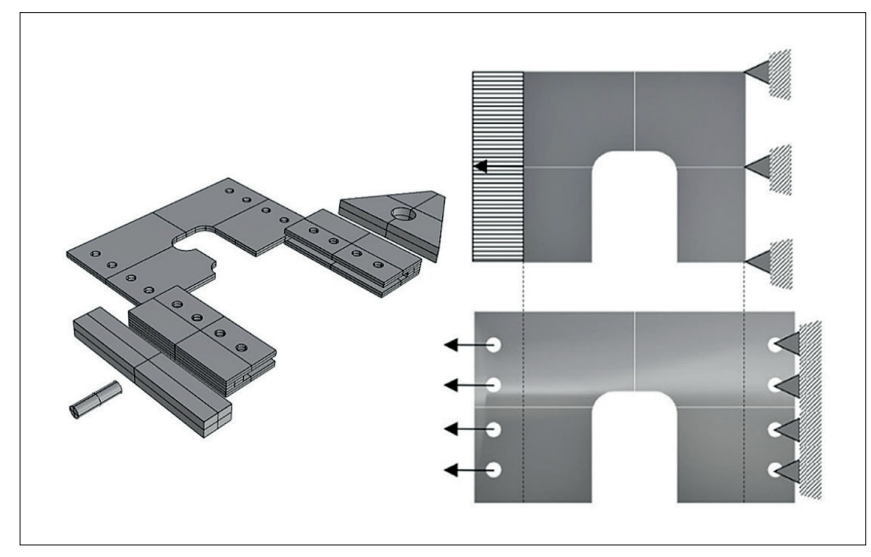

Fig. 7. (left) Arrangement of transition pieces for adaptation and coupling to the testing machine.(right) Comparison between initial and adapted geometry

\section{FINITE ELEMENT MODELLING}

Numerical modelling based on the extended finite element method (XFEM) by linear analysis (that is widely used in the process of fracture and crack growth) is used to obtain the results. However, this modelling approach has limitations in that it incurs a high computational cost and it is difficult to achieve convergence in some scenarios [23]. This approach incorporates certain degrees of freedom of the nodes that 
belong to the elements that contain the crack as obtained using enrichment functions, which are defined as the set of functions that allow for the establishment of any displacement near the crack as a combination of the same functions [24]. This research uses the XFEM employed by ANSYS ${ }^{\circledR}$ APDL 20 from the unstructured mesh method (UMM) implemented in the separating, morphing, adaptive, and remeshing technology (SMART) module. A standard coarse mesh is set using default 10 -node (quadratic) tetrahedral $[25,26]$ and solid elements $[27,28]$ and two refined elements at two levels; on the one hand, it is done in the eight drilled holes of the model, and on the other hand, a mesh of local character is achieved that adapts to the contour of the crack (Fig. 8) under a generic area of influence with a radius of $20 \mathrm{~mm}$ (whose aim is to refine the meshing near the crack and improve the quality of the results) and a standard element size of $2 \mathrm{~mm}$.

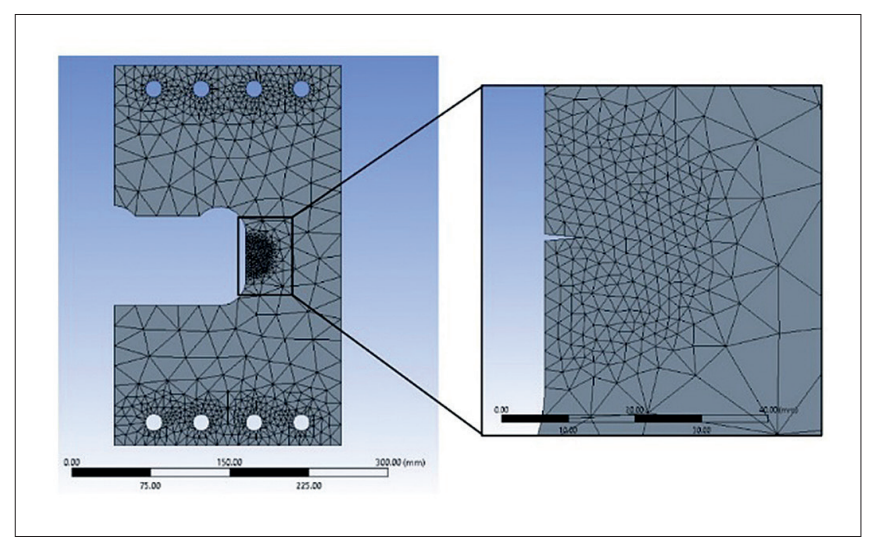

Fig. 8. Meshing (coarse and fine) pattern of specimen 2

Local meshing is updated during the crack propagation process (Fig. 9). The numerical model referring to specimen 1 comprises 17,858 nodes and 9,996 elements, while the numerical model referring to specimen 2 comprises 17,573 nodes and 9,866 elements.

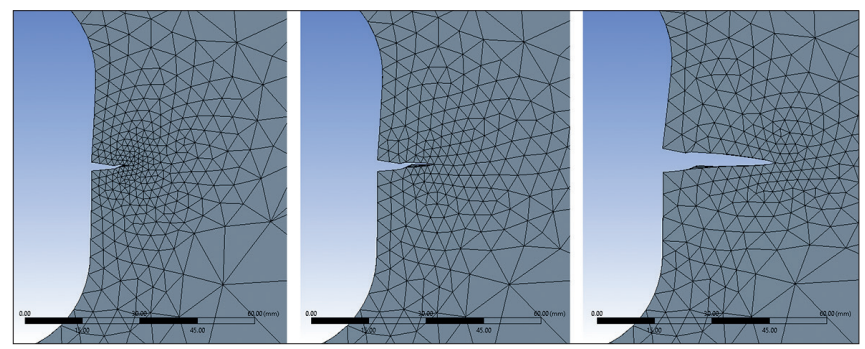

Fig. 9. Adaptive re-meshing technique in the fracture process in specimen 2

The correct structural correspondence between geometries shown in Fig. 7 is established by comparing the most representative values (von Mises stress and maximum displacement) of the two static regime tests, thereby obtaining differences in stresses and displacements that are translated into percentages of 3.31 and $4.5 \%$, respectively. The comparison, in terms of displacements, is done between the maximum displacements of the whole specimen (Fig. 10), while the comparison between von Mises stresses is carried out at the crack location.
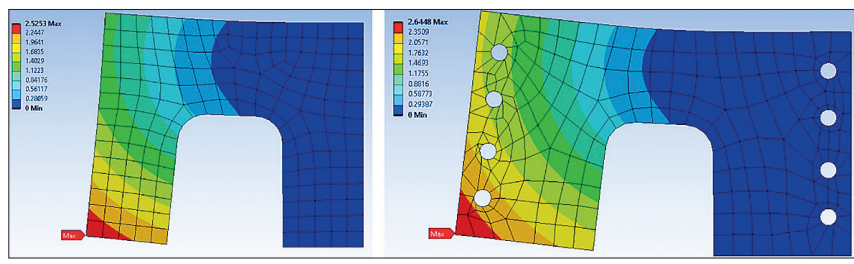

Fig. 10. Comparison between both geometries when determining the value of the maximum displacement of specimen 1

To assess the structural design and the results derived from it, the correlation between the two main geometric variables that occur in the testing process - crack length (a) and cut-out opening (crack mouth opening displacement, CMOD) - are studied. Figs. 11 and 12 show the numerical and test models for each specimen.

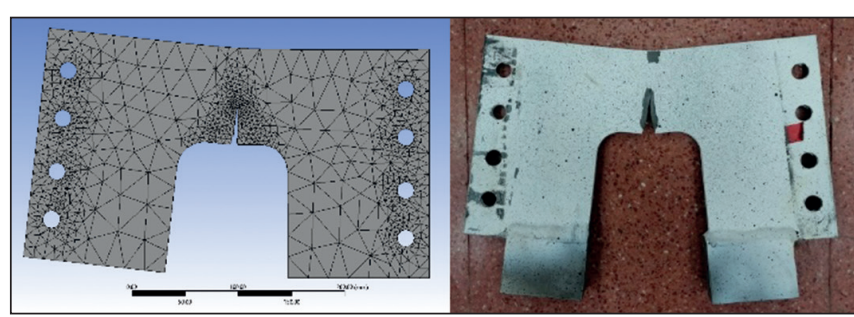

Fig. 11. Specimen 1 fracture process. (left) numerical model (right) test model

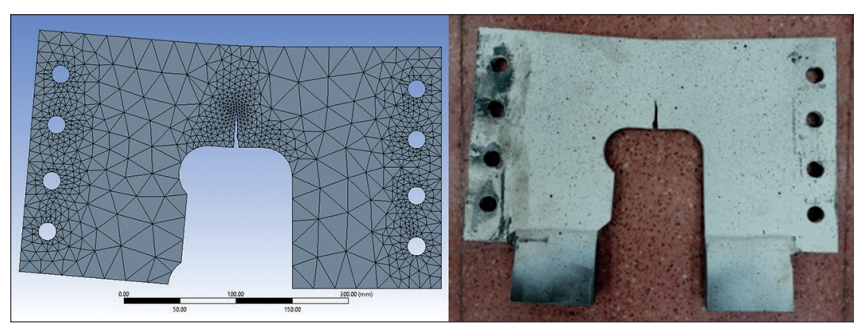

Fig. 12. Specimen 2 fracture process. (left) numerical model (right) test model

The analysis of both variables validates the numerical results obtained through the experimental tests and the correct arrangement of the specimens in the testing machine (Table 2).

Tab. 2. Comparison between numerical and experimental analysis for both specimens

\begin{tabular}{|c|c|c|c|c|}
\hline \multirow{2}{*}{ Specimen } & Analysis & $\begin{array}{c}\text { Crack } \\
\text { length, } \\
\mathrm{a}(\mathrm{mm})\end{array}$ & $\begin{array}{c}\text { CMOD } \\
(\mathrm{mm})\end{array}$ & $\begin{array}{c}\text { Difference } \\
(\%)\end{array}$ \\
\hline \multirow{2}{*}{1} & Numerical & & 124.85 & \multirow{2}{*}{32.96} \\
\cline { 2 - 2 } & Experimental & & 130 & \\
\hline \multirow{2}{*}{2} & Numerical & \multirow{2}{*}{30} & 109.95 & \multirow{2}{*}{2.69} \\
\cline { 2 - 2 } & Experimental & & 113 & \\
\hline
\end{tabular}

Table 2 shows the differences between both analyses (numerical and experimental) for each of the specimens; larger values in the experimental tests are attributed to uncertainties inherent to the physical crack growth mechanism derived from the fatigue phenomenon. Other uncertainties are associated with imperfections of the material at the microstructural level and the constrained plasticity effect. Eventually, others may be due to the testing machine and the way the dynamic load was applied. Another validation analysis to reveal the 


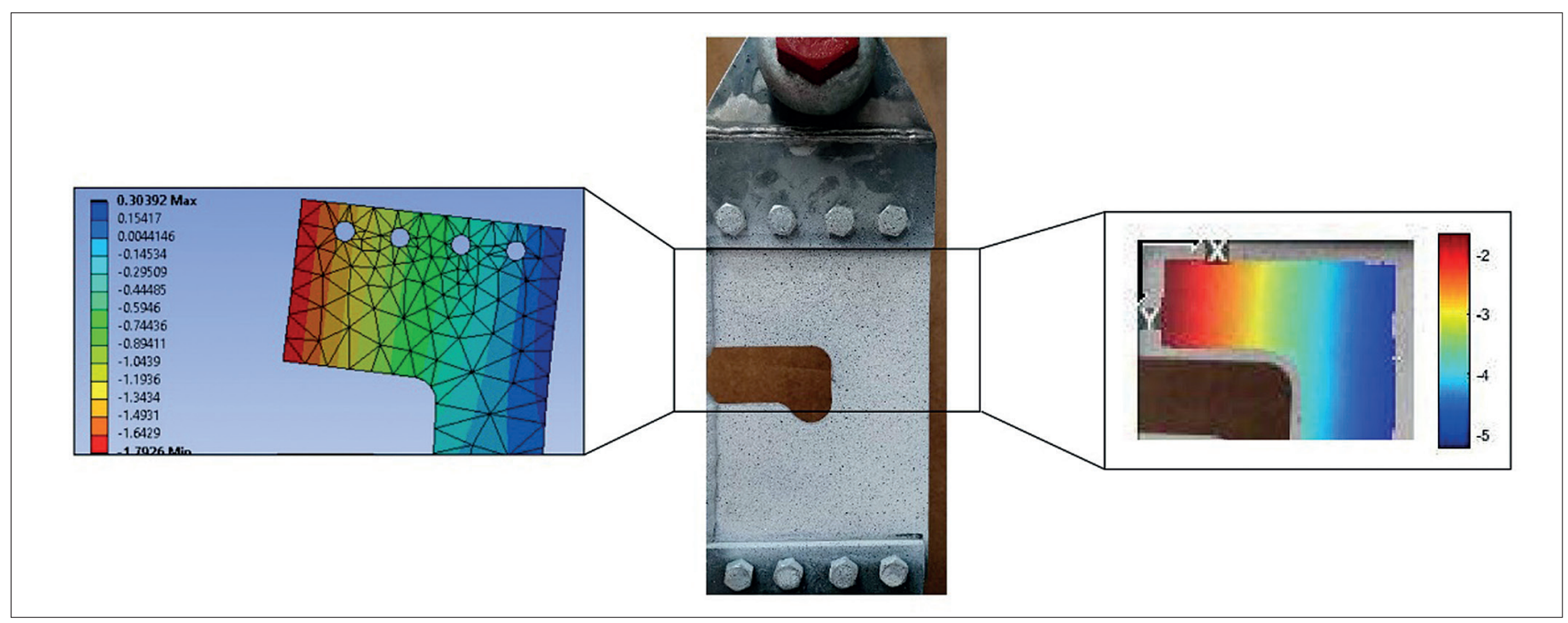

Fig. 13. Correspondence between DIC and FEM results from the strain field distribution (dimensions in $\mathrm{mm} / \mathrm{mm}$ )

model accuracy is carried out by comparing results at the experimental level by establishing the strain field distribution obtained by DIC $(1.85 \mathrm{~mm} / \mathrm{mm})$ and using the FEM technique $(1.79 \mathrm{~mm} / \mathrm{mm})$, with a difference between both procedures of 3\% (Fig. 13).

\section{RESULTS AND DISCUSSION}

\section{STRESS STATE}

The stress state in the original design scenario (loads and boundary conditions) is determined by means of the von Mises stress. Stress concentration is similar for both specimens; however, in the region of interest where the crack is located, the stress value is larger (approximately 1\%) in specimen 1 (Fig. 14).
The fatigue safety factor (FSF) is defined as a contour plot of the factor of safety with respect to a fatigue failure at a given design life (standard value of $1 \cdot 10^{9}$ cycles) $[29,30]$. Fig 15 depicts the direct influence of the geometric variable defining longitudinal spacing on the determination of the FSF distribution for specimen 2 .

The influence on the determination of the FSF value also results in a modification of the weight; the weight variable is determined for each combination formed by both specimens and longitudinal spacing values (Table 3 ).

Tab. 3. Weight comparison (in $\mathrm{kg}$ ) for each combination of specimens and longitudinal spacing values

\begin{tabular}{|c|c|c|c|}
\cline { 3 - 4 } \multicolumn{2}{c|}{} & Specimen 1 & Specimen 2 \\
\hline \multirow{3}{*}{$\begin{array}{c}\text { Spacing } \\
(\mathrm{mm})\end{array}$} & 400 & 1.97 & 2.06 \\
\cline { 2 - 4 } & 500 & 2.65 & 2.74 \\
\cline { 2 - 4 } & 600 & 3.32 & 3.41 \\
\hline
\end{tabular}
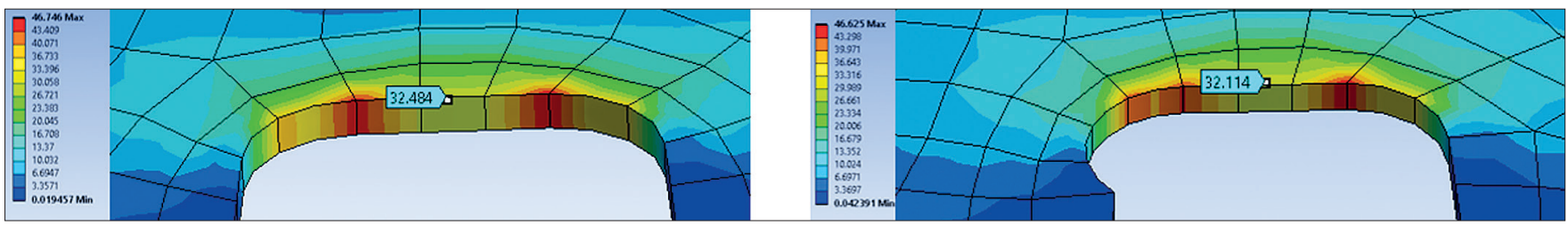

Fig. 14. Comparison between the von Mises stress (MPa) between both specimens in the region of interest

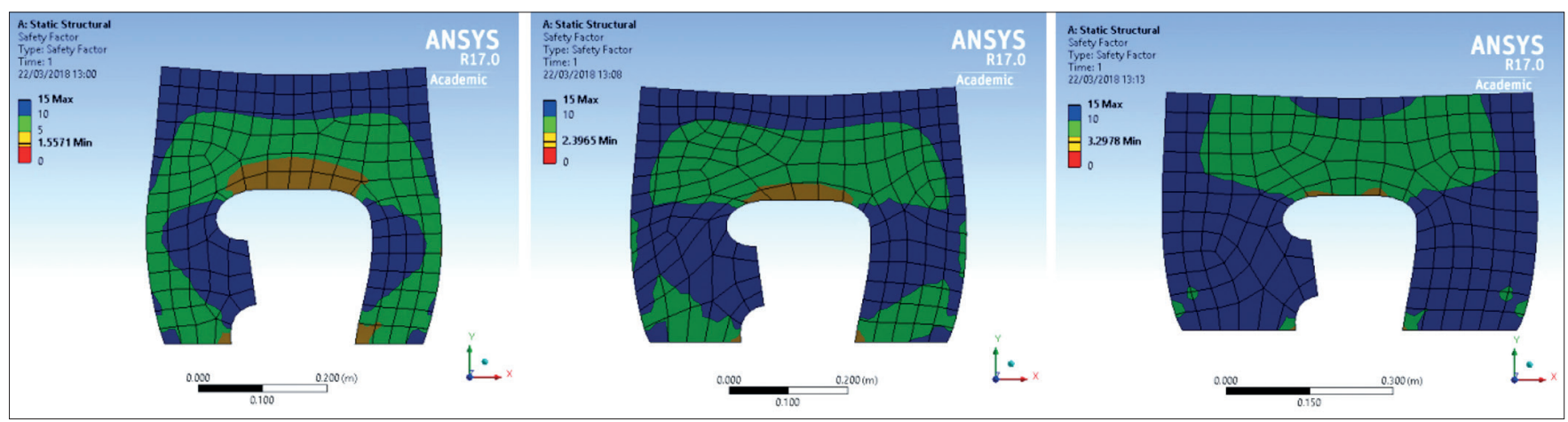

Fig. 15. Evolution of the FSF in specimen 2 for the different values of longitudinal spacing (400, 500, and $600 \mathrm{~mm}$, respectively) 
Fig. 16 shows the comparison of the behavior of the weight variable and the value of the minimum FSF under modifications of the longitudinal spacing for specimen 2 .

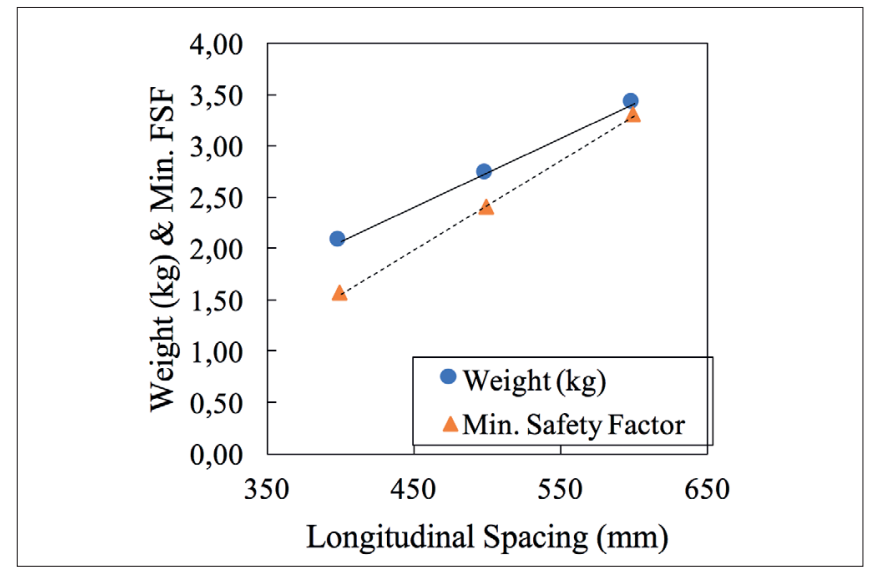

Fig. 16. Comparison of the evolution of the data concerning the weight and the minimum FSF in specimen 2 caused by modifications of the longitudinal spacing

Since the sub model is located in a transverse web whose dimensions are constant because the main particulars of the vessel do not change, the state of loads acting on the specimens maintains its initial value in the process of varying the thickness and longitudinal spacing. For the range of longitudinal spacing values, both variables have a linear trend with a sensitivity of min FSF larger than weight (approximately 22\%). To mitigate the loss of fatigue life, in terms of the minimum FSF, caused by the reduction of the longitudinal spacing (without the need for additional reinforcement elements), it is necessary to increase the thickness value, and the relationship between both variables (thickness and longitudinal spacing) is established to obtain the same minimum FSF value. An iterative process is conducted wherein it is necessary to fix an initial thickness $(20 \mathrm{~mm})$ and initial spacing $(600 \mathrm{~mm})$, and to make the extrapolation of the results more reliable for introducing two intermediate points $(550 \mathrm{~mm}$ and $450 \mathrm{~mm}$ ) that correspond to two new longitudinal spacing values. The initial combination of $600 \mathrm{~mm}$ longitudinal spacing and $20 \mathrm{~mm}$ thickness provides the design fatigue life and, in the range of longitudinal spacing values (400-600 mm), the stiffener and its cut-out (specimen 1 and specimen 2) keep their dimensions unchanged. The necessary increase in thickness is computed to reduce the effect of the decrease in longitudinal spacing and provide the same fatigue life as the initial situation for the same loading history (Table 4).

Tab. 4. Thickness and longitudinal spacing for the same fatigue life (FSF) values

\begin{tabular}{|c|c|c|}
\cline { 2 - 3 } \multicolumn{1}{c|}{} & Specimen 1 & Specimen 2 \\
\hline Spacing $(\mathrm{mm})$ & 20 & 20 \\
\hline 600 & 21.8 & 21.8 \\
\hline 550 & 23.2 & 23.2 \\
\hline 500 & 26.8 & 26.6 \\
\hline 450 & 30.5 & 30.2 \\
\hline 400 & \multicolumn{2}{|c|}{ Thickness $(\mathrm{mm})$} \\
\hline
\end{tabular}

There is an inverse relationship between the thickness and longitudinal spacing in the behavior between both variables, and this is determined via statistical treatment through a quadratic local regression model (Table 5 and Fig. 17). For both specimens, the local quadratic, linear, and logarithmic regression models have a correlation coefficient $\left(\mathrm{R}^{2}\right)$ of 0.99 , 0.95 , and 0.97 , respectively, so the local quadratic regression model is chosen as a better fit than the linear and logarithmic regression model by 3.66 and $1.74 \%$, respectively. For the same decrease in the longitudinal spacing (25\%), it is necessary to increase the thickness by $25.4 \%$ in specimen 1 , while an increase of $24.8 \%$ is required for specimen 2 .

Tab. 5. Quadratic regression coefficients for specimen 1 and $2\left(t=a s^{2}+b s+c\right)$

\begin{tabular}{|c|c|c|c|}
\cline { 3 - 4 } \multicolumn{1}{c|}{} & $\mathrm{a}$ & $\mathrm{b}$ & $\mathrm{c}$ \\
\hline Specimen 1 & & -0.2234 & 92.46 \\
\hline Specimen 2 & 0.0002 & -0.2104 & 88.76 \\
\cline { 3 - 4 } & & & \\
\hline
\end{tabular}

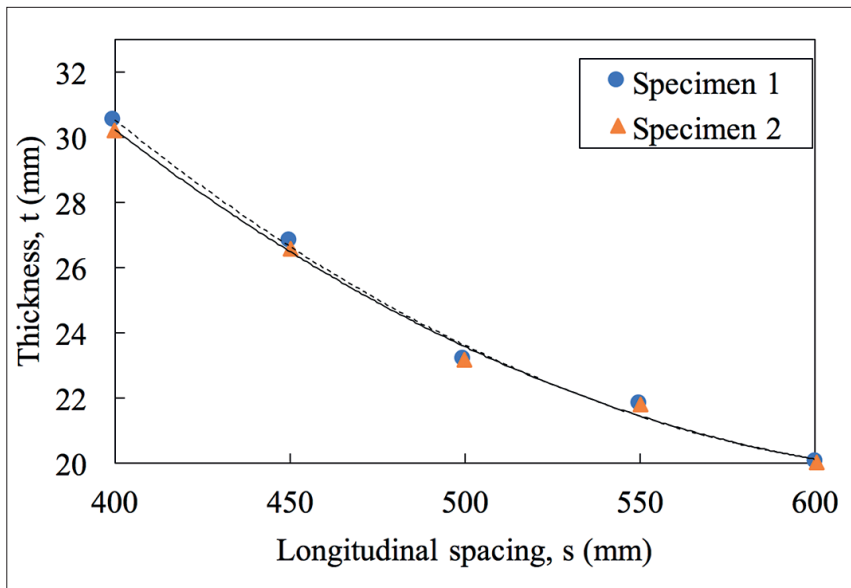

Fig. 17. Relationship between thickness and longitudinal spacing variables using local quadratic regression model for both specimens

\section{FATIGUE SENSITIVITY CURVES}

To consider the possible scenarios that generate load conditions that differ from the original conditions, fatigue sensitivity curves are calculated to provide a valuable tool for designing the structures. Fatigue sensitivity curves are defined as the graphs obtained by joining the points representing the available life for different values of the stress range expressed in terms of the loading history scale factor. The influence of scale factor on the increase and decrease of the stress range based on the initial load in the fatigue life is analyzed and investigated. For each combination between specimens and longitudinal spacing values, 25 possible equidistant variations of the stress ranges are considered, starting from the initial value (scale factor equals one) and extending to $\pm 50 \%$ with respect to the initial value, which includes a total of 150 numerical tests. Fatigue sensitivity curves are superimposed for each case of the three longitudinal spacing values and specimen 1 from the establishment of a standard design life of 1,000,000 cycles (Fig. 18). 


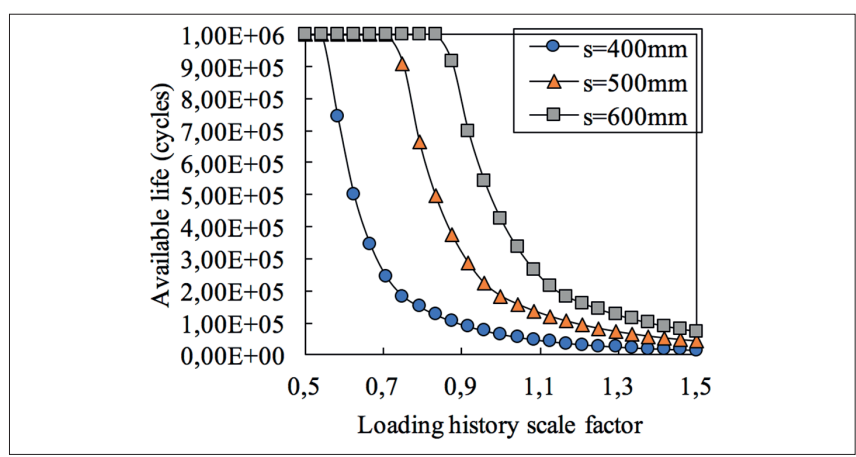

Fig. 18. Fatigue sensitivity curves for specimen 1

The union of all points of the fatigue sensitivity curves propose a possible extrapolation of the results by approximating the point cloud of each sub model tested via a common hyperbola. The sensitivity in terms of the modification of fatigue life tends to be inversely proportional to the scale factor used regardless of the value of the longitudinal spacing, with a very strong decrease in the fatigue life whose values tend to be adjusted as the scale factor increases. Fig. 18 shows the evolution of the fatigue life of specimen 1 for three possible values of the longitudinal spacing as the initial stress range in terms of loading history scale factor is changed. A common pattern is observed in the structural behavior regardless of the value of the longitudinal spacing. The decrease in fatigue life as a consequence of increasing the stress range is more pronounced at lower values of longitudinal spacing and at higher values of stress range (with respect to its design value). The number of fatigue life cycles tends to adjust for the different values of longitudinal stiffening.

\section{BIAXIALITY INDICATION}

Biaxiality indication (BI) is defined as the smaller principal stress divided by the larger principal stress, with the principal stress divided by the principal stress nearest zero being ignored [31]. A biaxiality of 0 corresponds to uniaxial stress, a value of -1 corresponds to pure shear, and a value of 1 corresponds to a pure biaxial state (Fig. 19).

The biaxial stress state of specimen 1 shows a clear increasing trend; however, the value has a convex shape for the rest of the options, and it reaches the maximum for the $500 \mathrm{~mm}$ spacing. For the pure shear state, the biaxial stress state trend is decreasing with concave and convex forms, where there is no considerable difference between all sub models and the low spacing values are quite dispersed, while there is a difference between the sub models at high spacing values. Furthermore, there are only two options where it is slightly increasing but almost imperceptible, and that is for specimen 2 (Fig. 20).

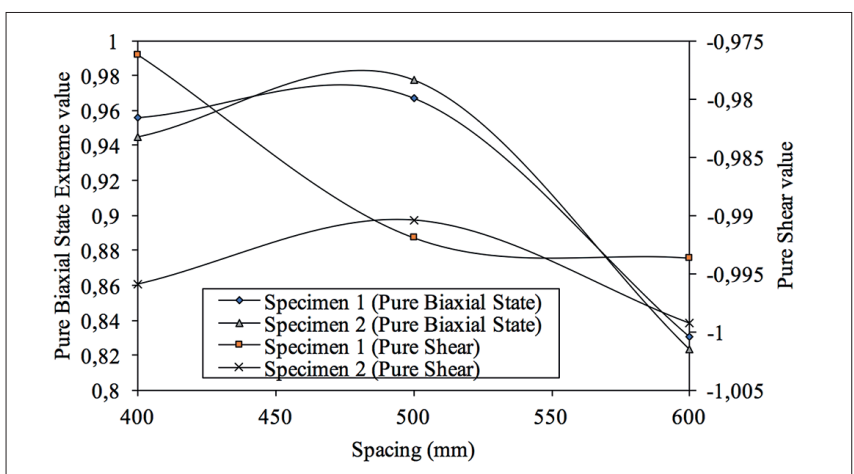

Fig. 20. Pure biaxial state and pure shear for both specimens

The relationship between BI and minimum FSF concepts is established; the zone of low values of the FSF corresponds with a uniaxial stress state, and the next zone, in the order of importance, is the cut-out vertical surroundings where the pure shear stress state predominates. Finally, in the load side ans low values of longitudinal spacing governs the pure biaxial stress state.

\section{CRACK GROWTH}

From experimental tests, the crack growth process is obtained by characterizing the crack length and the number of load cycles applied, and a quadratic regression model is established from nine $(n=9)$ measurements (Fig. 21$)$.

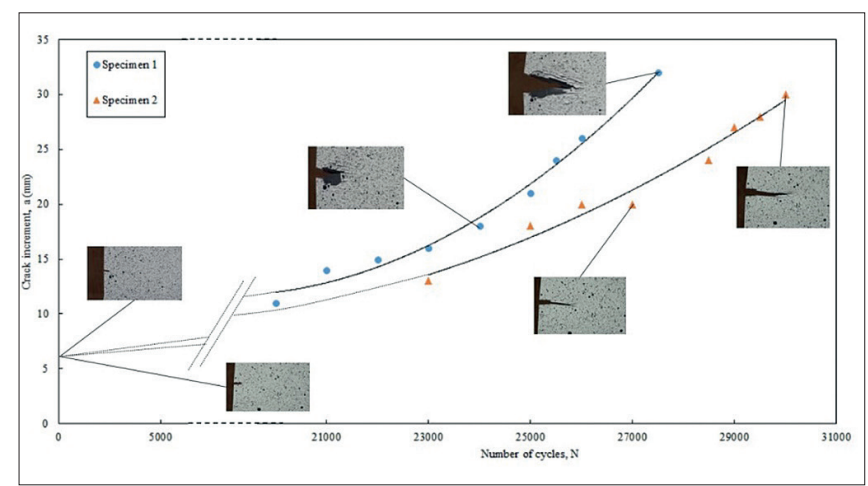

Fig. 21. Evolution of crack length (a) for the number of cycles for both specimens
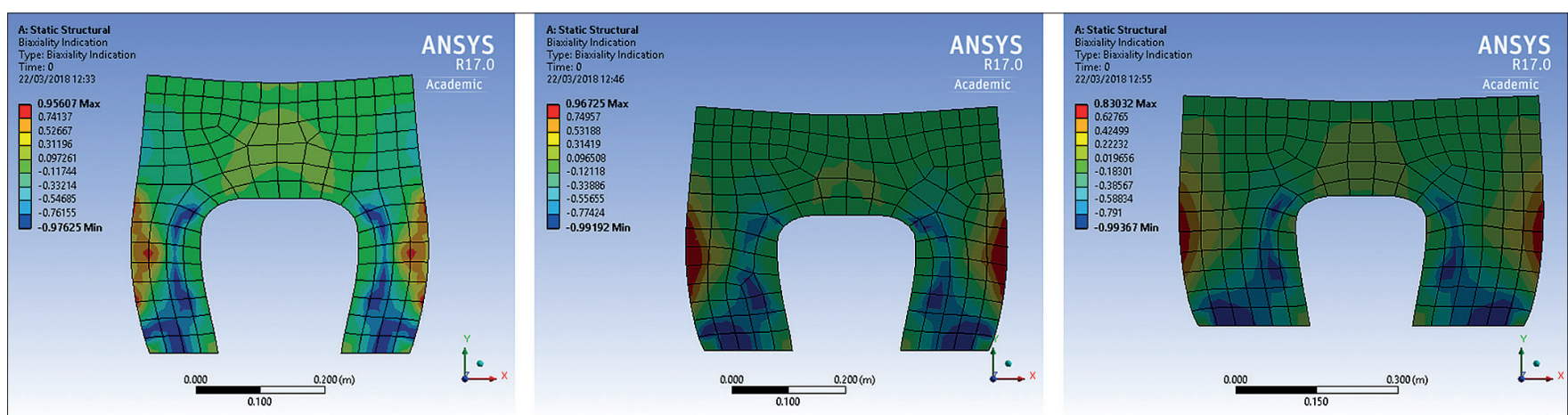

Fig. 19. Distribution of biaxiality indication for specimen 1 and each of the values of the longitudinal spacing (400, 500, and $600 \mathrm{~mm})$ 
The procedure comprises crack tip advances by the fatigue following the Paris law [32],

$$
\frac{d a}{d N} \simeq \frac{\Delta a}{\Delta N}=\frac{a_{i}-a_{i-1}}{N_{i}-N_{i-1}}=C \Delta K^{m}
$$

where $C$ and $m$ represent constants that are dependent on the load and boundary conditions and $\Delta K$ denotes the range of the stress intensity factor given by

$$
\begin{gathered}
\Delta K_{i}=\left(K_{\text {máx }}-K_{\text {min }}\right)=\left(\sigma_{\text {máx }}-\sigma_{\text {min }}\right) \cdot Y\left(a_{m, i}\right) \cdot \sqrt{\pi \cdot a_{m, i}} \\
\text { with } a_{m}=\frac{a_{i}+a_{i-1}}{2}
\end{gathered}
$$

where $Y\left(a_{m, i}\right)$ denotes a dimensionless geometric factor that updates its value with each crack length in the fracture process depending on specimen geometry, actual crack length $a_{m, i}$ and nominal stress $\sigma$ [33]. Two random increments of the crack size evolution record are studied to obtain the two constants that define the Paris Law, and a system of two equations with two unknowns is acquired from the determination of the maximum and minimum stress level (using the load history and geometry of the specimen) and the crack length associated to that increment. The resolution leads to the expression

$$
\frac{d a}{d N}=\left(2.94 \cdot 10^{-8}\right) \Delta K^{22}
$$

The graphical output is represented in a log-log diagram (Fig. 22).

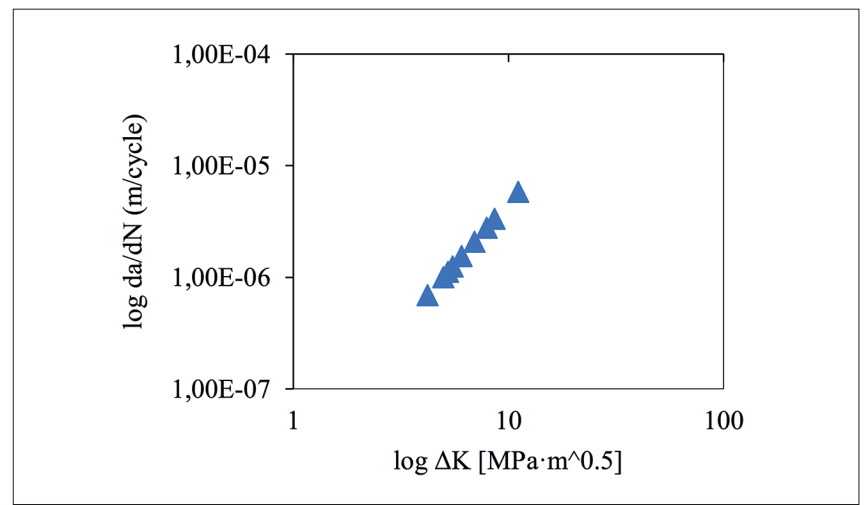

Fig. 22. Relationship between crack propagation rate and stress intensity factor range

The values of the constants that define the crack growth rate from the Paris law are appropriate according to the literature [34]. An analysis of variance (ANOVA) is performed to check the accuracy of the proposed results using a linear regression model (Table 6).

Tab. 6. Analysis of variance (ANOVA)

\begin{tabular}{|c|c|c|c|}
\hline Concept & $\begin{array}{c}\text { Degrees } \\
\text { of freedom }\end{array}$ & $\begin{array}{c}\text { Sum } \\
\text { of squares }\end{array}$ & $\begin{array}{c}\text { Mean } \\
\text { squares }\end{array}$ \\
\hline $\begin{array}{c}\text { Sum of Squares } \\
\text { Regression (SSR) }\end{array}$ & 1 & $2.06 \cdot 10^{-11}$ & $2.067 \cdot 10^{-11}$ \\
\hline $\begin{array}{c}\text { Sum of Squares Error } \\
\text { (SSE) }\end{array}$ & $\mathrm{n}-2$ & $5.61 \cdot 10^{-13}$ & $8.02 \cdot 10^{-14}$ \\
\hline $\begin{array}{c}\text { Sum of Squares Total } \\
\text { (SST) }\end{array}$ & $\mathrm{n}-1$ & $2.12 \cdot 10^{-11}$ & - \\
\hline
\end{tabular}

The difference between the measured value and the set value using the regression model (SSE) is obtained from the residuals plot (Fig. 23) from the regression line (with their respective standard error; $3.24 \cdot 10^{-7}$ for the y-intercept and $4.61 \cdot 10^{-8}$ for the slope). The statistical model obtains a standard error of the regression model of $2.83 \cdot 10^{-7}$, a correlation coefficient $\left(\mathrm{R}^{2}\right)$ of 0.97 , and an F-factor of 257.63 .

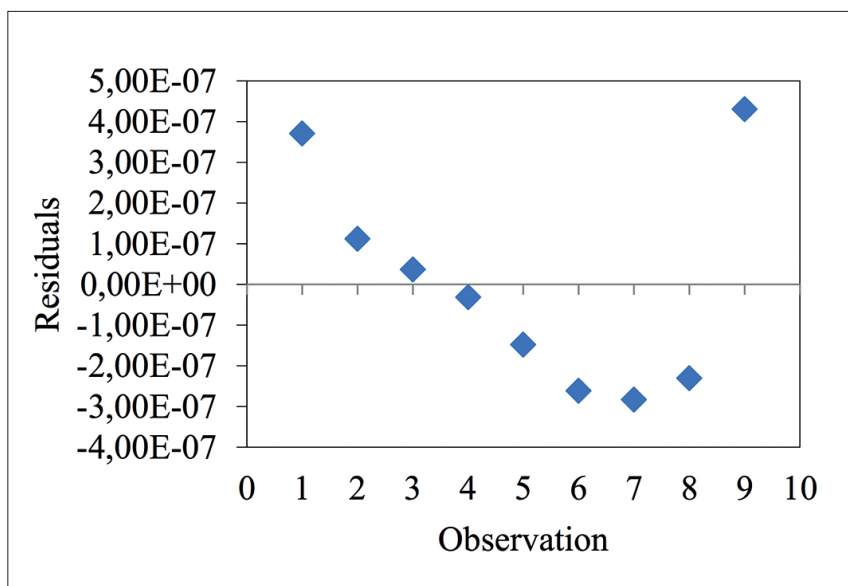

Fig. 23. Residuals plot

\section{STRESS INTENSITY FACTOR}

The stress intensity factor (SIF) is used as the controlling parameter for evaluating the critical state of a crack and for determining the design criteria and structural behavior. Fig. 24 shows the relationship between the crack length and the SIF value for each tested specimen from a numerical approach.

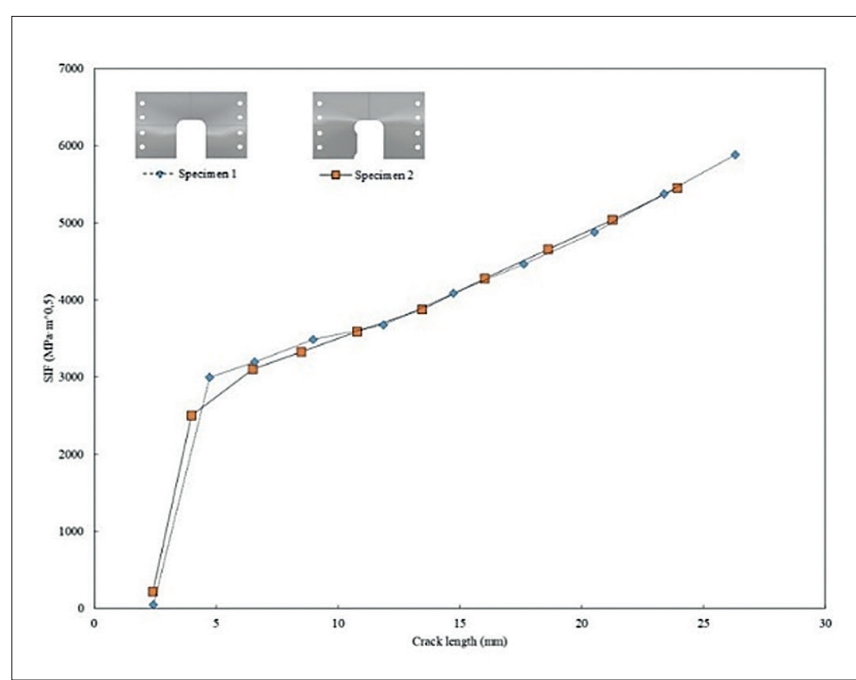

Fig. 24. Evolution of the maximum value of the stress intensity factor in both specimens in the crack growth process

The distribution of the SIF on the crack front is characterized by the non-uniformity of SIF during the crack growth process, regardless of the specimen geometry. Fig. 25 reports the non-uniform value of the SIF for two crack lengths in specimen 1 . 


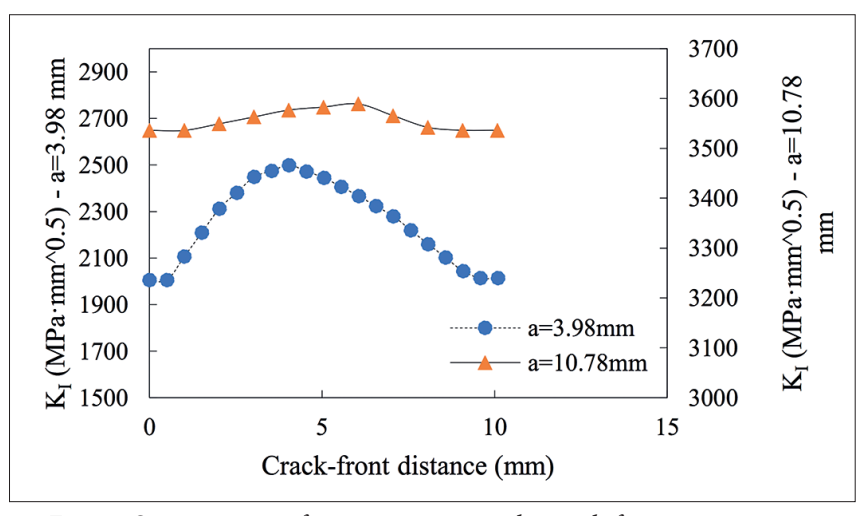

Fig. 25. Stress intensity factor variation on the crack-front in specimen 1

Fig. 26 shows the same previous case from the point of view of the structural assessment.

From the obtained results, the SIF distribution at the crack front cannot be used as a design parameter due to the nonuniformity of the stress intensity factor along the crack front for each of the tested specimens. However, it can be used in terms of the maximum value because it follows a linear trend along the crack growth process (Fig. 26) that can be extrapolated by a linear regression model and used in the design as a merit value. Table 7 shows the coefficients of the linear regression model for each of the specimens and the correlation coefficient $\left(\mathrm{R}^{2}\right)$ from the data represented in Fig. 24.

Tab. 7. Linear regression model $(S I F=m \cdot a+n)$ for each specimen on the behavior at the maximum SIF value under crack growth (a)

\begin{tabular}{|c|c|c|c|c|}
\hline & $\mathrm{m}$ & $\mathrm{n}$ & $\mathrm{R}^{2}$ & $\begin{array}{c}\text { Mean } \\
\text { error (\%) }\end{array}$ \\
\hline Specimen 1 & 145.33 & 2238.1 & 0.9861 & 1.39 \\
\hline Specimen 2 & 119.8 & 2217.1 & 0.9929 & 0.71 \\
\hline
\end{tabular}

\section{CONCLUSIONS}

This study reported an experimental procedure for determining the mechanical behavior and fatigue design of a typical marine structure based on different geometries of specimens, obtaining the best of them in structural terms, and determining the degree of influence and relationship between the variables that define the study model and the boundary conditions present. Based on the results, it can be concluded that specimen 2 has a slight improvement over specimen 1 and that the decision to modify the longitudinal spacing variable has a significant influence on the determination of fatigue life. This fact was determined by a larger material arrangement, and the decision to increase the FSF with the cost of the weight increase was justified from a structural behavior point of view because the tendency to increase the FSF was greater than that of the weight at equal modifications of the longitudinal spacing.

A quadratic relationship was observed between the variables thickness and longitudinal stiffener spacing that allows for the extrapolation of the fatigue life behavior of the specimens in the presence of modifications in any of its variables. The hyperbolic character that correlated the fatigue life variable with the variation of the stress range of the loading history was obtained independently of the value of the variable that defined the longitudinal spacing. The constants of the Paris law were determined (which are validated according to the statistical values that support the proposed regression model) and consequently, the structural behavior of this type of structure is obtained. These results can be extrapolated to other ships with similar geometric structural details.

Obtaining the SIF in the crack front in the crack propagation procedure leads to two conclusions: the SIF exhibits an increasing linear trend as the crack front advances regardless of the specimen tested, and there is no relationship of similarity and extrapolation of the SIF value between both specimens and between different crack lengths within the crack growth process of the same specimen. The magnitude of KI varies along the crack front, and this variation depends on the specimen thickness and boundary conditions.

\section{REFERENCES}

1. W. Fricke, A. Von Lileienfeld-Toal, and H. Paetzoldt, "Fatigue strength investigations of welded details of stiffened plate
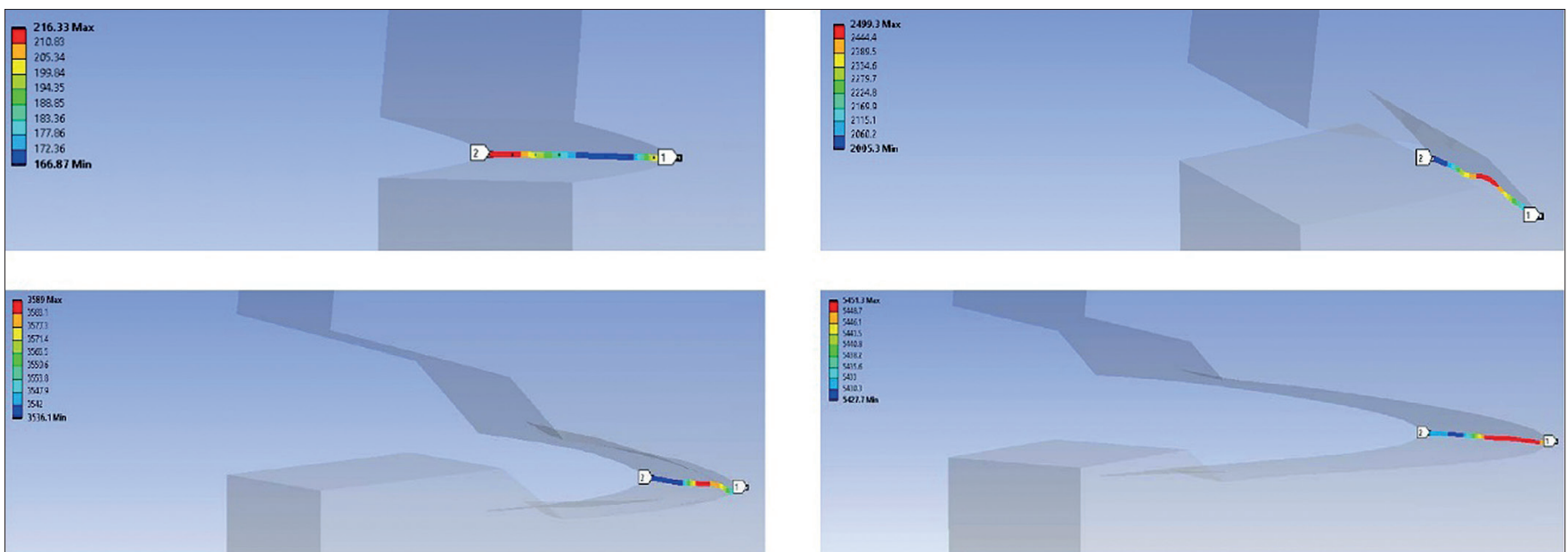

Fig. 26. Time evolution of the stress intensity factor on the crack front in specimen 1 
structures in steel ships," International Journal of Fatigue, vol.34(1), pp. 17-26, 2012. doi: 10.1016/j.ijfatigue.2011.01.021.

2. J. Kuniala, "Fatigue Analysis of 3-Dimensional Ship Structural Detail," Aalto University School of Engineering. Thesis for the degree of Master of Science in Technology, 2016.

3. W. Fricke, "Fatigue analysis of welded joints: state of development," Marine Structures, vol. 16(3), pp. 185-200, 2003. doi: 10.1016/S0951-8339(02)00075-8.

4. W. Fricke, O. Doerk, and C. Weissenbord, "Comparison of different calculation methods for structural stresses at welded joints," International Journal of Fatigue, vol. 25(5), pp. 359-369, 2003. doi: 10.1016/S0142-1123(02)00167-6.

5. W. Fricke and H. Paetzold, "Full-scale fatigue tests of ship structures to validate the $\mathrm{S}-\mathrm{N}$ approaches for fatigue strength assessment," Marine Structures, vol. 23(1), pp. 115-130, 2010. doi: 10.1016/j.marstruc.2010.01.004.

6. I. Lotsberg, "Fatigue design of plated structures using finite element analysis," Ships and Offshore Structures, vol. 1(1), pp. 45-54, 2006. doi: 10.1533/saos.2005.0006.

7. W. Fricke, "Recent developments and future challenges in fatigue strength assessment of welded joints," Proc Inst Mech Eng C J Mech Eng Sci., vol. 229(7), pp. 1224-1239, 2014. doi: $10.1177 / 0954406214550015$.

8. K. Tran Nguyen, Y. Garbatov, and C. Guedes Soares, "Fatigue damage assessment of corroded oil tanker details based on global and local stress approaches," International Journal of Fatigue, vol. 43, pp. 197-206, 2012. doi: 10.1016/j. ijfatigue.2012.04.004.

9. M. Aygül, "Fatigue Analysis of Welded Structures Using the Finite Element Method," Thesis for the Degree of Licenciate of Engineering. Chalmers University of Technology, 2012.

10. I. Poutiainen, P. Tanskanen, and G. Marquis, "Finite element methods for structural hot spot stress determination a comparison of procedures," International Journal of Fatigue, vol. 26(11), pp. 1147-1157, 2004. doi: 10.1016/j. ijfatigue.2004.04.003.

11. Z. Wang, "Fatigue Behavior and Failure Assessment of Plate Connections in Ship Shaped Structures," PhD thesis. National University of Singapore, 2008.

12. H. M. Westergaard, "Bearing Pressures and Cracks," Journal of Applied mechanics, vol. 6, pp. A49-53, 1939.

13. G. R. Irwin, "Analysis of stresses and strains near the end of a crack traversing a plate," Journal of Applied mechanics, vol. 24, pp. 361-364, 1957.
14. M. L. Williams, "On the Stress Distribution at the Base of a Stationary Crack," Journal of Applied mechanics, vol. 24(1), pp. 109-114, 1956.

15. F. Erdogan and G. C. Sih, "On the crack extension in plates under plane loading and transverse shear," Journal of basic Engineering, vol. 85(4), pp. 519-527, 1963. doi: 10.1115/1.3656897.

16. M. Hussain, S. Pu, and J. Underwood, "Strain energy release rate for a crack under combined mode I and mode II," Proceedings of the 1973 National Symposium on Fracture Mechanics, Part II (ASTM International), pp. 2-28, 1974. doi: 10.1520/STP33130S.

17. M. Chafi and A. Boulenouar, "A Numerical Modelling of Mixed Mode Crack Initiation and Growth in Functionally Graded Materials," Materials Research, vol. 22(3), pp. e20180701, 2019. doi : 10.1590/1980-5373-mr-2018-0701

18. A. Carpinteri, "Stress-singularity and generalized fracture toughness at the vertex of re-entrant corners," Engineering Fracture Mechanics, vol. 26(1), pp. 143-155, 1987. doi: 10.1016/0013-7944(87)90086-5.

19. M. Strandberg, "Fracture at V-notches with contained plasticity," Engineering Fracture Mechanics, vol. 69(3), pp. 403-415, 2002. doi: 10.1016/S0013-7944(01)00079-0.

20. J. D. Carroll, W. Abuzaid, J. Lambros, and H. Sehitoglu, “ High resolution digital image correlation measurements of strain accumulation in fatigue crack growth," International Journal of Fatigue, vol. 57, pp. 140-150, 2013. https://doi. org/10.1016/j.ijfatigue.2012.06.010.

21. J. Blaber, B. Adair, and A. Antoniou, "NCorr: Open-Source 2D Digital Image Correlation Matlab Software," Experimental Mechanics, vol. 55, pp. 1105-1122, 2015. doi: 10.1007/ s11340-015-0009-1.

22. R. Branco, F. V. Antunes, J. A. Martins Ferreira, and J. M. Silva, "Determination of Paris law constants with a reverse engineering technique," Engineering Failure Analysis, vol. 16, pp. 631-638, 2009. doi: 10.1016/j.engfailanal.2008.02.004.

23. I. Galic, I. Cular, V. Kresimir, and Z. Tonkovic, "Comparison of SIF solutions obtained by XFEM and conventional FEM or cracks in complex geometries like valve body," Procedia Structural Integrity, vol. 13, pp. 2109-2113, 2018. doi: 10.1016/j.prostr.2018.12.200.

24. N. Möes, J. Dolbow, and T. Belytschko, "A finite element method for crack growth without remeshing," International Journal for Numerical Methods in Engineering, vol. 46, pp. 131-150, 1999. doi:10.1002/(sici)1097-0207(19990910)46:1\%3c131::aidnme726\%3e3.0.co;2-j. 
25. F. Zhou, J. Molinari, and Y. Li, “Three-dimensional numerical simulations of dynamic fracture in silicon carbide reinforced aluminium," Engineering Fracture Mechanics, vol. 71, pp. 1357-1378, 2004. doi: https://doi.org/10.1016/ S0013-7944(03)00168-1.

26. A. O. Ayhan, "Three-dimensional fracture analysis using tetrahedral enriched elements and fully unstructured mesh," International Journal of Solids and Structures, vol. 48, pp. 492-505, 2011. doi: https://doi.org/10.1016/j. ijsolstr.2010.10.012.

27. W. Huang, Y. Garbatov, and C. Guedes Soares, "Fatigue reliability assessment of a complex welded structure subjected to multiple cracks," Engineering Structures, vol. 56, pp. 868-879, 2013. doi: https://doi.org/10.1016/j. engstruct.2013.06.011

28. T. Ulleland and M. Svensson, "Stress Concentration Factors in Side Shells Longitudinals Connected to Transverse Webframes," Proceedings of the Eleventh International Offshore and Polar Engineering Conference, 2001.

29. M. S. Vidhya and K. V. M. Christina, "Fatigue Life, Fatigue Damage, Fatigue Factor of Safety, Fatigue Sensitivity, Biaxiality Indication and Equivalent Stress of a Radial Connecting Rod," International Research Journal of Engineering and Technology, vol. 7(9), pp. 1499-1502, 2020.

30. H. R. Wasmi, M. Q. Abdullah, and O. A. Jassim, “Testing and Estimation Fatigue Life of a Flange Connection used in Power Plant by ANSYS," International Journal of Current Engineering and Technology, vol. 6(4), pp. 1302-1306, 2006.

31. A. Bhanage and K. Padmanabhan, "Design for fatigue and simulation of glass fibre/epoxy composite automobile leaf spring," ARPN Journal of Engineering and Applied Sciences, vol. 9(3), pp. 196, 2014.

32. P. C. Paris and F. Erdogan, "A critical analysis of crack propagation laws," Journal of Basic Engineering, vol. 85 (4), pp. 528-534, 1963. doi: 10.1115/1.3656900.

33. N. Perez, Fracture Mechanics. Springer US, 2004.

34. M. Mlikota, S. Staib, S. Schmauder, and Z. Bozic, "Numerical determination of Paris law constants for carbon steel using a two-scale model," Journal of Physics: Conference Series, vol. 843, pp. 012042, 2017. doi: 10.1088/1742-6596/843/1/012042.

\section{CONTACT WITH THE AUTHORS}

\section{Arturo Silva-Campillo}

e-mail:a.silva@upm.es

Universidad Politécnica de Madrid Avenida de la Memoria 28040 Madrid

SPAIN

\section{Juan Carlos Suárez-Bermejo}

e-mail: juancarlos.suarez@upm.es

Universidad Politécnica de Madrid Avenida de la Memoria 28040 Madrid

SPAIN

\author{
Miguel Ángel Herreros-Sierra \\ e-mail:miguelangel.herreros@upm.es \\ Universidad Politécnica de Madrid \\ Avenida de la Memoria \\ 28040 Madrid \\ SPAIN
}

